\section{Pricing not enough for deep carbon cuts}

Carbon pricing dominates the climate-policy debate on the basis of its promise to abate greenhouse-gas emissions at least cost. Although this holds true for incremental emissions reductions (see K. Gillingham et al. Nature 551,27-29; 2017), we question whether it can spur the changes needed for decarbonization, a goal of the Paris agreement.

Carbon pricing is more vulnerable to political opposition than are other climate policies, resulting in low prices that produce marginal reductions through efforts such as fuel switching. These have not stopped new investment in emitting technologies such as coal-fired power generation.

More countries are thus resorting to blunt technology phase-outs. Canada, France, Italy, the United Kingdom and others pledged to end coal use by 2030 at last month's climate summit in Bonn, Germany. Although effective, such tools can increase costs for emitters and for society when they cause retirement of investments before the end of their useful economic life.

Climate change is caused by many market failures, calling for a portfolio of policy instruments. Because of the focus on carbon pricing, research into the design, effects and interactions of other policies, including phase-out mandates, has lagged behind. As decarbonization efforts progress, we should re-evaluate the role of carbon pricing in the policy mix. Michael Mehling Massachusetts Institute of Technology,

Cambridge, Massachusetts, USA. Endre Tvinnereim Uni Research Rokkan Centre, Bergen, Norway. mmehling@mit.edu

\section{How to spare half a planet}

James Watson and Oscar Venter discuss the practicalities of conserving half of Earth's terrestrial ecosystems (Nature 550, 48-49; 2017). An

unanswered question is whether the non-conserved half can support the growing food needs of the human population.

Field assessment of the abundance patterns of more than 1,600 species of birds, trees, grasses, sedges, butterflies and beetles on four continents indicates that the answer may depend on farming methods (A. Balmford et al. Daedalus 144, 57-75; 2015). Many of these species depend on wild habitats - underscoring calls for ambitious conservation targets — but are relatively insensitive to boosting yields on farmland. Tying increased production on already-cleared land to the protection of natural land cover elsewhere could thus free up space to meet the habitat needs of these species (see B. Phalan et al. Science 351, 450-451; 2016).

Farming improvements should increase yields sustainably while reducing environmental externalities and enhancing local livelihoods. Unless conservationists engage with agricultural and development experts to limit the space needed for food production, calls to give pre-eminence to nature on half of our planet will be ignored.

Andrew Balmford, Rhys Green University of Cambridge, UK. apb12@cam.ac.uk

\section{Medical legacy of sanctions in Iran}

People with haemophilia in Iran live with the disabling legacy of international economic sanctions against the country, which were lifted in 2016 (see also S. Shahabi et al. Nature 520, 157; 2015).

Iran has the highest number of people with haemophilia in the Middle East. Timely administration of the bloodclotting protein factor VIII, which is deficient in haemophilia, can prevent physical disability.

According to the annual global survey by the World Federation of Hemophilia and reports from the director of Iran's Haemophilia

Society, the mean per capita

use of factor VIII in Iran was

0.5 international units (IU)

after sanctions were imposed in

2006, down from 1.6 before. The

drop was a result of a shortage

of the protein and inflated

prices during the sanctions era. It left about 1,000 people who have haemophilia with physical impairment as a result of bleeding into their joints, and some individuals died from uncontrolled bleeding (see go.nature.com/2jfj9ow).

The lifting of sanctions has made a big difference: the per capita use of factor VIII in Iran has now risen to $2.7 \mathrm{IU}$. We hope that the slow improvement in the country's public-health services and pharmaceutical research can continue uninterrupted by political interference.

Reza Heidari, Mostafa

Akbariqomi, Gholamreza

Tavoosidana Tehran University of Medical Sciences, Tehran, Iran. g-tavoosi@tums.ac.ir

\section{Snow-leopard status is spot on}

As the authors of the latest Red List assessment of the status of the snow leopard (Panthera uncia) for the International Union for Conservation of Nature (IUCN), we take issue with Achyut Aryal's view that its upgrade from endangered to vulnerable is based on "unrealistic" population estimates and could adversely affect conservation efforts (Nature 550, 457; 2017).

Aryal incorrectly suggests that the status change stems from recently published population figures that are higher than previously thought (Snow Leopards Elsevier, 2016). For precautionary purposes, however, the IUCN assessment relied solely on the long-standing and widely accepted lowest possible global population estimate of 4,000 (see go.nature.com/2ncj9na).

Aryal speculates that a report by the wildlife trade monitoring network TRAFFIC could underestimate the poaching of snow leopards in remote locations. However, unsubstantiated poaching allegations would not alter the Red List outcome. Endangered status requires a documented high rate of population decline, which is no longer evident for this species.

Although conservation funding can favour endangered species, the IUCN prohibits financial considerations when assessing species for the Red List. The list is strictly a measure of extinction risk, hence vulnerable status (high risk) should not affect conservation initiatives. Tom McCarthy ${ }^{\star}$ Panthera, Redmond, Washington, USA. tmccarthy@panthera.org ${ }^{\star}$ On behalf of 5 correspondents (see go.nature.com/2y7b4me for full list)

\section{Standardize future device connections}

Computing advances generally seem like a boon - except when they render lab equipment defunct before its time. I have had to stop using an expensive spectroscopic device because its software runs only on an old computer with obsolete connections. In a tablet world, even the ubiquitous USB connection port is at risk of disappearing. I suggest that a universal connection for all devices should be created and retained in future machines.

If different types of connection are allowed to proliferate, local data storage on external hard drives, central storage devices or USB sticks could also become obsolete. We do not want to reach a situation in which we can still read Marie Curies's lab notes from the nineteenth century but not what our last $\mathrm{PhD}$ student did. As the only standard connection to most devices is USB, it is not too late to safeguard it as a future world standard.

Ricardo Borges University of $\mathrm{La}$ Laguna, Tenerife, Spain. rborges@ull.es 